\title{
Evaluation of Salt Tolerance in Italian Ryegrass at Different Developmental Stages
}

\author{
Yan Xie ${ }^{1,2, \dagger}$, Xiaoying Liu ${ }^{1,2, \dagger}$, Maurice Amee ${ }^{1,2}$, Hua Yu ${ }^{1,2}$, Ye Huang ${ }^{1,2}$, Xiaoning Li ${ }^{3}$, Liang Chen ${ }^{1,2}$, \\ Jinmin $\mathrm{Fu}^{3, *}$ and Xiaoyan Sun ${ }^{4, *}$
}

1 CAS Key Laboratory of Plant Germplasm Enhancement and Specialty Agriculture, Wuhan Botanical Garden, Chinese Academy of Sciences, Wuhan 430074, China; xieyan@wbgcas.cn (Y.X.); liuxiaoying17@mails.ucas.ac.cn (X.L.); maurice.amee@gmail.com (M.A.); yuhua18@mails.ucas.ac.cn (H.Y.); huangye18@mails.ucas.ac.cn (Y.H.); chenliang888@wbgcas.cn (L.C.)

2 Center of Economic Botany, Core Botanical Gardens, Chinese Academy of Sciences, Wuhan 430074, China

3 School of Resources and Environmental Engineering, Ludong University, Yantai 264025, China; lixiaoning0724@126.com

4 Jiangxi Engineering and Technology Research Center for Ecological Remediation of Heavy Metal Pollution, Institute of Microbe, Jiangxi Academy of Sciences, Nanchang 330096, China

* Correspondence: jfu@wbgcas.cn (J.F.); sunxiaoyan@jxas.ac.cn (X.S.)

+ These authors contributed equally to this work.

check for

updates

Citation: Xie, Y.; Liu, X.; Amee, M.; Yu, H.; Huang, Y.; Li, X.; Chen, L.; Fu, J.; Sun, X. Evaluation of Salt Tolerance in Italian Ryegrass at Different Developmental Stages. Agronomy 2021, 11, 1487. https://doi.org/ 10.3390 / agronomy 11081487

Academic Editors: Bronwyn Barkla and Andrew Eamens

Received: 7 May 2021

Accepted: 20 July 2021

Published: 27 July 2021

Publisher's Note: MDPI stays neutral with regard to jurisdictional claims in published maps and institutional affiliations.

Copyright: (C) 2021 by the authors. Licensee MDPI, Basel, Switzerland. This article is an open access article distributed under the terms and conditions of the Creative Commons Attribution (CC BY) license (https:/ / creativecommons.org/licenses/by/ $4.0 /)$.

\begin{abstract}
Soil salinity is one of the major abiotic stresses that continues to threaten plant growth and agricultural productivity. Screening germplasm with salinity tolerance is therefore necessary. This study was designed to evaluate salt tolerance based on the integrated tolerance index. Fifteen Italian ryegrass cultivars were used to evaluate the degree of genotypic variation in salt tolerance at the germination and vegetative growth stages of plant development. Evident variations in salt tolerance were observed at the germination stage under $255 \mathrm{mM} \mathrm{NaCl}$ treatment. Root growth rate, chlorophyll content, and germination rates played a vital role in determining salt tolerance. Based on combined attributes at the germination and vegetative growth stages, Gongniu, Chuangnong, Splendor, and Abundant were identified as the most tolerant cultivars. Furthermore, the constant crude protein, lower neutral detergent fiber, and acid detergent fiber contents were measured under salinity. Compared to the control, the cultivars Tetragold, Abundant, Splendor, Muyao, Harukaze, Tegao, Dongmu 70, and Doraian were identified to have high forage quality under salt stress. Finally, we selected Splendor and Abundant as the cultivars that expressed the highest degree of salt tolerance based on combined attributes related to germination, salt tolerance, and overall forage quality. In addition, gene expression analysis between salinity tolerant and sensitive cultivars revealed that the gene response to photosystem and carbohydrate synthesis may have played a mediating role in providing tolerance to salt stress.
\end{abstract}

Keywords: Italian ryegrass; salt tolerance; evaluation; germination stage; vegetative growth stage; forage quality; RNA-seq

\section{Introduction}

The salinity of soil or water is a major abiotic stress that hinders plant growth and limits the production capabilities of agricultural soils worldwide [1]. Salinity issues are caused by a variety of factors, such as climatic conditions, human activity, and landforms. Soils are classified as saline when the effective concentration value (ECe) reaches $4 \mathrm{dS} / \mathrm{m}$ $(40 \mathrm{mM} \mathrm{NaCl})$ or more, which significantly reduces the yield of most crops. Globally, more than 800 million hectares of land are affected by salt, equating to more than $6 \%$ of the world's total land area [2]. In China, 100 million hectares of soil are affected by salt and the area of saline land is increasing every year [3].

The identification of salt-tolerant plants and their cultivation could be a promising solution for land reclamation with saline soils. Therefore, screening of salt-tolerant 
germplasm is important for determining the existence of a genetic basis for breeding purposes [4]. Collecting and assessing germplasm that is suitable for saline soils is the first step in finding genetic variation in salt tolerance. Recently, research on salt tolerance in forage species has become increasingly important in saline soils. In China, only marginal land, such as saline soils, is available for planting forage species due to competition between the increasing population and decreasing farmland. Therefore, there is an increasingly high need for genetic improvement of salt-tolerant forage species.

Italian ryegrass (Lolium multiflorum L.) is an annual, outcrossing, and mainly selfincompatible commercially important forage crop. It is widely cultivated for the production of hay and silage worldwide including southern China due to its high forage production and digestibility. The yield of Italian ryegrass in alkaline soil is higher than that in acid soil $[5,6]$. Therefore, Italian ryegrass has been considered to be one of the most promising grasses for moderately saline environments.

Previous studies have demonstrated that variances in salt tolerance exist among different Italian ryegrass cultivars $[7,8]$. Germination is the first stage in the plant life cycle for all crops. The ability to germinate quickly is critical to generate a high yield in saline soils. However, the germination behavior of Italian ryegrass can also be modified at low concentrations of salt in the substrate, which in turn results in reductions in growth rate and forage crop yields [7]. To date, due to the lack of a comprehensive evaluation system, only a few Italian ryegrass genotypes have been screened for salt tolerance at the seed germination stage [7-10]. Developing an effective evaluation system would be highly helpful for screening salinity-tolerant genotypes of Italian ryegrass [1,11].

In addition to rapid growth, high dry matter production and high forage quality are desirable characteristics for promising forage varieties. In grass species, saline environments induce adaptive changes in morphological, physiological, and biochemical traits of plants, including changes in growth rate, osmotic adjustment, photosynthesis efficiency, and nutrition value [12-14]. Plant adaptation to salt is a complex phenomenon. Previous studies have shown that plant growth rate is an important index for evaluating salt stress tolerance since photosynthesis, cell expansion, and cell division are greatly inhibited at high salt concentrations $[15,16]$. The reduced growth and use of cellular organelles and other resources is an adaptive strategy for the plant to survive in undesirable conditions [17]. Additionally, salt injury to plants has been attributed to lower osmotic potential [18]. Lower osmotic potential also reduces the ability of the plant to absorb water [2]. Salt stress can also decrease chlorophyll content and leaf water content [2].

Forage quality is related to the animals' effective and efficient conversion of feed into nutrients. Digestibility and nitrogen content of grasses are principal determinants of forage quality. Previous studies have indicated that abiotic stress, such as salt, would alter the quality of forage [19]. The development of integrated indices of forage quality evaluation is clearly a worthy goal. Some integrated indices, such as relative feed value and relative forage quality, have been used widely in the United States. However, these indices are not sufficiently accurate in the assessment of practical differences between forages of similar classifications, especially for grasses [20]. Grading index (GI) is a forage grading integrative index proposed by Zheng et al. [20] and was defined as the forage voluntary intake of available energy after being corrected by crude protein and neutral detergent fiber contents. GI serves as an easy and effective method to comprehensively evaluate forage quality $[20,21]$.

To develop an effective evaluating system under salinity stresses, 15 Italian ryegrass cultivars were evaluated for their morpho-physiological and gene expression changes under salt stress conditions at different developmental stages. The objectives of this study were: (1) to determine the characteristics of seed germination under degrees of $\mathrm{NaCl}$ stress; (2) to evaluate salt tolerance based on the integrated tolerance index calculated with fuzzy subordinate functions; (3) to determine the forage quality-related traits under $\mathrm{NaCl}$ stress; and (4) to identify suitable salt-tolerant cultivars of Italian ryegrass. 


\section{Materials and Methods}

\subsection{Plant Materials and Growth Condition}

Fifteen cultivars, Tetragold, Angus No. 1, Abundant, Splendor, Double Barrel, Chuangjiang No. 2, Chuangnong No. 1, Muyao, Harukaze, Gongniu, Chuangnong, Tegao, Dongmu 70, Doraian, and Big Boss of Italian ryegrass were used in this study. Seeds were surface-sterilized with $75 \%$ ethanol for $1 \mathrm{~min}$ followed by $10 \%$ sodium hypochlorite $(\mathrm{NaClO})$ for $3 \mathrm{~min}$ and then rinsed five times with distilled water. All experiments were carried out in a greenhouse at standard conditions $\left(25 / 20^{\circ} \mathrm{C}\right.$ for day/night, $14 \mathrm{~h}$ light $/ 10 \mathrm{~h}$ dark, $60 \%$ relative humidity, and average photosynthetically active radiation of $\left.720 \mu \mathrm{mol} \mathrm{m}^{-2} \mathrm{~s}^{-1}\right)$.

\subsection{Experiment 1: Seed Germination}

Fifty sterilized seeds with uniform size were selected and sown evenly in a Petri dish ( $9 \mathrm{~cm}$ in diameter) filled with three layers of filter paper. The filter paper was moistened with $4 \mathrm{~mL}$ distilled water containing $0 \mathrm{mM}$ (control, no $\mathrm{NaCl}$ added to the distilled water), $85 \mathrm{mM}, 170 \mathrm{mM}$, or $255 \mathrm{mM} \mathrm{NaCl}$. The treatment for each cultivar had four replicates (200 seeds total). During the seed germination stage, the moisture in the Petri dishes was maintained by adding the treatment solution accordingly. All the Petri dishes were placed in an incubator and maintained for 12 days under dark conditions.

The germination percentage or rate (\%) was recorded on the $3 \mathrm{rd}, 5 \mathrm{th}, 7 \mathrm{th}, 9 \mathrm{th}$, and 12 th days, and seeds were considered to have germinated when the emerging shoot was approximately $50 \%$ of the length of the seed. The germination rates (GR) were used for subsequent analysis on the 12th day. The shoot length of ten uniform seedlings in each Petri dish was measured on the 7th day. The GR was calculated as the total number of seeds germinated. The inhibition rate of shoot elongation was calculated according to the following equation (Equation (1)) [22]:

$$
\mathrm{I}=\frac{(\mathrm{Dc}-\mathrm{Dt})}{\mathrm{Dc}}
$$

where I is the inhibition of elongation in \%; Dc is the average length of shoot under control conditions $(\mathrm{mm})$; and $\mathrm{Dt}$ is the average length of shoot grown under the tested $\mathrm{NaCl}$ concentration $(\mathrm{mm})$. The germination energy was calculated according to the method described by Wang et al. [23].

Germination energy $(\mathrm{GE}, \%)=$ (number of germinating seeds $/$ number of total seeds per treatment after germination for 5 days) $\times 100$

Germination index (GEI, \%) was calculated as described in the Association of Official Seed Analysis (1983), using the following equation:

$$
\text { GEI }=\frac{\text { Number of germinated seeds }}{\text { Days of first count }}+\cdots+\frac{\text { Numder of germinated seeds }}{\text { Days of final count }}
$$

\subsection{Experiment 2: Evaluation Test}

\subsubsection{Plant Materials and Growth Conditions}

To obtain seedlings, sterilized seeds were germinated in Petri dishes $(9 \mathrm{~cm}$ in diameter) filled with filter paper under conditions of constant darkness. After 5 days of incubation, uniformly germinated seeds were selected and raised in plastic pots $(15 \mathrm{~cm}$ in diameter and $20 \mathrm{~cm}$ deep) filled with sand. The pots were put into the greenhouse. During the growth period, plants were watered twice a week and fertilized weekly with half-strength Hoagland's solution. After 30 days of establishment, the roots of the plants ( 15 plants per pot) were rinsed thoroughly with distilled water, and then the plants were transplanted into new plastic pots $(10 \mathrm{~cm}$ diameter and $18 \mathrm{~cm}$ tall) filled with coarse silica sand as the plant anchor medium. Pot bottoms consisted of a coarse nylon screen allowing roots to 
freely grow into the solutions. Pots were suspended over tubs containing $35 \mathrm{~L}$ of constantly aerated half-strength Hoagland's solution. The tubs were refilled every other day and renewed weekly. All plants were maintained in the greenhouse at the standard conditions described previously for 2 weeks to allow the adaptation to hydroponic culture conditions and the recovery of uptake capabilities of roots and leaves. At the beginning of the salt treatment, the plant shoots were hand-clipped at $20 \mathrm{~cm}$ height, and roots were clipped back to the bottoms of the pots to allow the plants to reach full maturity and develop uniform and equal sized roots and shoots.

\subsubsection{Treatment and Experimental Design}

Through a pre-experiment, we found that $255 \mathrm{mM} \mathrm{NaCl}$ concentration is too high for screening Italian ryegrass, and $85 \mathrm{mM} \mathrm{NaCl}$ concentration is too low. Therefore, we chose two $\mathrm{NaCl}$ concentrations (100 mM and $200 \mathrm{mM}$ ) between 85-255 mM to evaluate salt tolerance. After pre-adaptation, plants were subjected to three salinity levels: $0 \mathrm{mM}$ (control, CK), $100 \mathrm{mM}$, and $200 \mathrm{mM} \mathrm{NaCl}$. Salinity was increased by daily increments of $50 \mathrm{mM} \mathrm{NaCl}$ until a final salinity level was reached. After the final salinity level $(200 \mathrm{mM})$ was reached ( $4 \mathrm{~d}$ after the initiation of the salt treatment), the plants were exposed to final salinity concentrations for 3 weeks. During the period of salt exposure, the culture solutions were aerated with an air pump and changed twice a week to maintain the desired nutrient levels. The experiment was arranged in a randomized complete block design with three replicates for each treatment and the pots were re-randomized every two days. At the end of the experiment, shoot growth rate (SGR), root growth rate (RGR), chlorophyll content $(\mathrm{Chl})$, leaf relative water content (LWC), electrolyte leakage (EL), and ion contents ( $\mathrm{Na}$ and $\mathrm{K}$ ) were determined.

\subsubsection{Measurements}

Canopy height was measured in four positions in each pot using a ruler and was averaged. SGR was the difference in canopy height before and after the 3 week treatment period. RGR was determined only for roots elongating from the nylon screen at the pot bottom.

Chl was recorded using the chlorophyll meter (SPAD-502, Minolta, Camera Co. Ltd., Osaka, Japan). The content of each individual treatment was recorded from seven fully expanded leaves with three measurements taken for each leaf.

LWC was measured according to the method of Sun et al. [24]. Leaf EL was measured according to $\mathrm{Hu}$ et al. [25].

Crude protein (CP) was evaluated according to the Kjeldahl method (AOAC 1999) [26]. Crude fat (CF) was measured by extracting samples in petroleum ether using the Soxherm apparatus based on the Soxhlet method [27]. Crude ash (CA) and water-soluble carbohydrate (WSS) were measured according to Zhang [28]. Neutral detergent fiber excluding residual ash (NDF) was determined according to the method of Palmonari et al. [29]. Sodium sulfite was not used and amylase was used only with wheat bran in the determination of NDF. Acid detergent fiber excluded residual ash (ADF) was measured using the method of AOAC [27]. GI was estimated according to the following equations adapted from $\mathrm{Hu}$ et al. [20]:

$$
\mathrm{GI}=\left(\mathrm{NE}_{\mathrm{L}} \times \mathrm{CP} \times \mathrm{VDMI}\right) / \mathrm{NDF}
$$

where:

$$
\begin{gathered}
\mathrm{NE}_{\mathrm{L}}(\text { net energy for lactation, } \mathrm{MJ} / \mathrm{kg})=[1.085-(0.0150 \times \mathrm{ADF})] \times 9.29 \\
\mathrm{VDMI}(\text { voluntary dry matter intake, } \mathrm{kg} / \mathrm{d})=1.2 \times \mathrm{BW} / \mathrm{NDF}
\end{gathered}
$$

Ion contents ( $\mathrm{Na}$ and $\mathrm{K}$ ) were measured according to Li et al. [14]. 
2.3.4. Evaluation of Salt Tolerance by an Integrated Evaluation System

For a single parameter, salt injury index (SI) was calculated as:

$$
\mathrm{SI}=\frac{(\text { Control }- \text { Treatment })}{\text { Control }} \times 100 \%
$$

Salt-tolerant comprehensive evaluation of all cultivars was accessed by subordinate function and standard deviation coefficient methods using the SI under $200 \mathrm{mM}$ (because the effects of salt stress on different traits varied markedly under $200 \mathrm{mM} \mathrm{NaCl}$ concentration at the vegetative growth stage) or $255 \mathrm{mM} \mathrm{NaCl}$ (because the threshold for impaired germination was $255 \mathrm{mM}$ for Italian ryegrass) concentrations [30,31]. The value of each evaluation index was calculated by the following equations:

$$
\begin{gathered}
X(u)=\frac{X-X \min }{X \max -X \min } \\
X(u)=1-\frac{X-X m i n}{X m a x-X m i n} \\
\overline{X j}=1 / n \sum_{i=1}^{n} X i j \\
V j=\frac{\sqrt{\sum_{i=1}^{n}(X i j-\overline{X j})^{2}}}{\overline{X j}} \\
W j=\frac{V j}{\sum_{j=1}^{m} V j} \\
D=\sum_{j=1}^{n}[u(x j) * W j]
\end{gathered}
$$

Firstly, data of indexes were standardized by using the subordinate function [Equations (8) and (9)]. If an index was negatively correlated with $\mathrm{NaCl}$ tolerance, the membership value was estimated by the anti-membership function [Equation (9)]. Otherwise, it was calculated by Equation (8). Here, $X(u)$ is the subordinate function value of the $\mu$ th indicator, $X$ is the observed value of an indicator, and Xmax and Xmin represent the maximum and minimum value of the indicator, respectively. $\overline{X j}$ is the mean of the $j$ th evaluation index, $n$ is the number of cultivars, and $X i j$ represents the $j$ th evaluation index of the $i$ th cultivar [Equation (10)]. $V j$ is the coefficient of the standard deviation of the jth evaluation index, and $X j$ represents the $j$ th evaluation index of cultivars [Equation (11)]. $W j$ is the weighted coefficient of the $j$ th evaluation index [Equation (12)]. $u(x j)$ is the subordinate function value of the $j$ th evaluation index. $D$ indicates the integrated values for salt tolerance in Italian ryegrass [Equation (13)]. The lower the value of $D$, the higher the salt tolerance.

\subsection{Experiment 3: Gene Expression Analysis}

\subsubsection{Plant Materials and Treatment}

The salt-tolerant (Abundant) and salt-sensitive (Angus No. 1) cultivars were used for transcriptome analysis. Treatments and growing conditions were the same as in Experiment 2. After 2 weeks of hydroculture, all plants of each cultivar were divided into two groups. One group was transferred to a fresh half-strength Hoagland's solution (CK), while the other was moved into an identical solution but containing $200 \mathrm{mM} \mathrm{NaCl}$ (salt treatment). The leaf samples were harvested for transcriptome analysis at $12 \mathrm{~h}$ after the salt treatment began, immediately placed in liquid nitrogen, and stored at $-80{ }^{\circ} \mathrm{C}$ until analyzed. 


\subsubsection{RNA-Seq and Data Analysis}

We selected sensitive cultivar Angus No. 1 and tolerant cultivar Abundant to investigate the differences of gene expression upon salt stress with RNA-seq. For each cultivar, three biological replicates of salt-treated and control plants were sequenced. Leaves of selected cultivars were ground to fine powder in liquid nitrogen and total RNA was extracted with Trizol reagent according to the manufacturer's instructions (Invitrogen). Sequencing libraries were generated using NEBNext ${ }^{\circledR}$ Ultra $^{\mathrm{TM}}$ RNA Library Prep Kit for Illumina ${ }^{\circledR}$ (NEB, Illumina, San Diego, CA, USA) following the manufacturer's recommendations. Briefly, mRNA was purified from total RNA using poly-T oligo-attached magnetic beads. Fragmentation was carried out using divalent cations under elevated temperature in NEBNext First Strand Synthesis Reaction Buffer (5X). First-strand cDNA was synthesized using random hexamer primer and M-MuLV Reverse Transcriptase (RNase H-). Second strand cDNA synthesis was subsequently performed using DNA Polymerase I and RNase H. Remaining overhangs were converted into blunt ends via exonuclease/polymerase activities. After adenylation of $3^{\prime}$ ends of DNA fragments, NEBNext Adaptors with hairpin loop structures were ligated to prepare for hybridization. To select cDNA fragments of preferentially 250 300 bp in length, the library fragments were purified with AMPure Xp system (Beckman Coulter, Beverly, MA, USA). Then 3 uL USER Enzyme (NEB, USA) was used with size-selected, adaptor-ligated cDNA at $37^{\circ} \mathrm{C}$ for $15 \mathrm{~min}$ followed by $5 \mathrm{~min}$ at $95^{\circ} \mathrm{C}$ before PCR. Then PCR was performed with Phusion High-Fidelity DNA polymerase, Universal PCR primers, and Index (X) Primer. PCR products were purified (AMPure $\mathrm{Xp}<$ system) and library quality was assessed on the Agilent Bioanalyzer 2100 system.

After removing the adapter sequence from all reads, Transcriptome was assembled using Trinity [32] with min_kmer_cov set to 2 and all other parameters set to default. Differential gene expression was quantified using DESeq package against the assembled transcript and the assembled transcripts were annotated by NCBI BLAST tools against Swiss-Prot, GO, and KEGG databases. Gene Ontology (GO) enrichment analysis of the differentially expressed genes (DEGs) was implemented by the GOseq R packages based on Wallenius' non-central hypergeometric distribution which can adjust for gene length bias in DEGs, and KEGG pathways enrichment analysis was performed using KOBAS software to test the statistical enrichment of the differentially expressed genes.

\subsection{Statistical Analysis}

Data were expressed as the means $\pm \mathrm{SD}$ (standard deviation). Statistical analyses were performed using SPSS Version 20.0 software. Data of cultivars under different treatments were subjected to a one-way analysis of variance (ANOVA) and mean separations were performed using least significant difference multiple range tests, with $p<0.05$ as the significance criteria. For comparison between cultivars, the Tukey test was performed with $p<0.05$ as the significance criteria. Repeated measures analysis was used to analyze seed germination rate response to $\mathrm{NaCl}$ concentration in different periods.

\section{Results}

\subsection{Variation of Seed Germination Indexes under $\mathrm{NaCl}$ Treatment}

The GR for each cultivar under different $\mathrm{NaCl}$ concentrations are shown in Figures 1 and S1. Compared with the control, there are no significant differences in GR for all 15 cultivars when exposed to $85 \mathrm{mM} \mathrm{NaCl}$ (Figures 1 and S1). However, when the $\mathrm{NaCl}$ concentration reached $170 \mathrm{mM}, 9$ of 15 cultivars (Angus No. 1, Abundant, Double Barrel, Muyao, Harukaze, Tegao, Dongmu 70, Doraian, and Big Boss) showed evident CGR reductions, while all the other cultivars were not significantly different. When treated with $255 \mathrm{mM} \mathrm{NaCl}$, the CGR was severely inhibited and even completely inhibited in four cultivars (Angus No. 1, Double Barrel, Chuangnong No. 1, and Dongmu 70). The final GRs of cultivars Tegao and Big Boss dropped below $50 \%$ under $255 \mathrm{mM} \mathrm{NaCl}$ treatment. Unexpectedly, the GR of cultivar Abundant appeared to not be affected by $255 \mathrm{mM} \mathrm{NaCl}$ 
treatment, via this cultivar displaying a strong salinity tolerance at the germination stage (Figures 1 and S1).

\section{The relationship between germination rate and salt concentration}

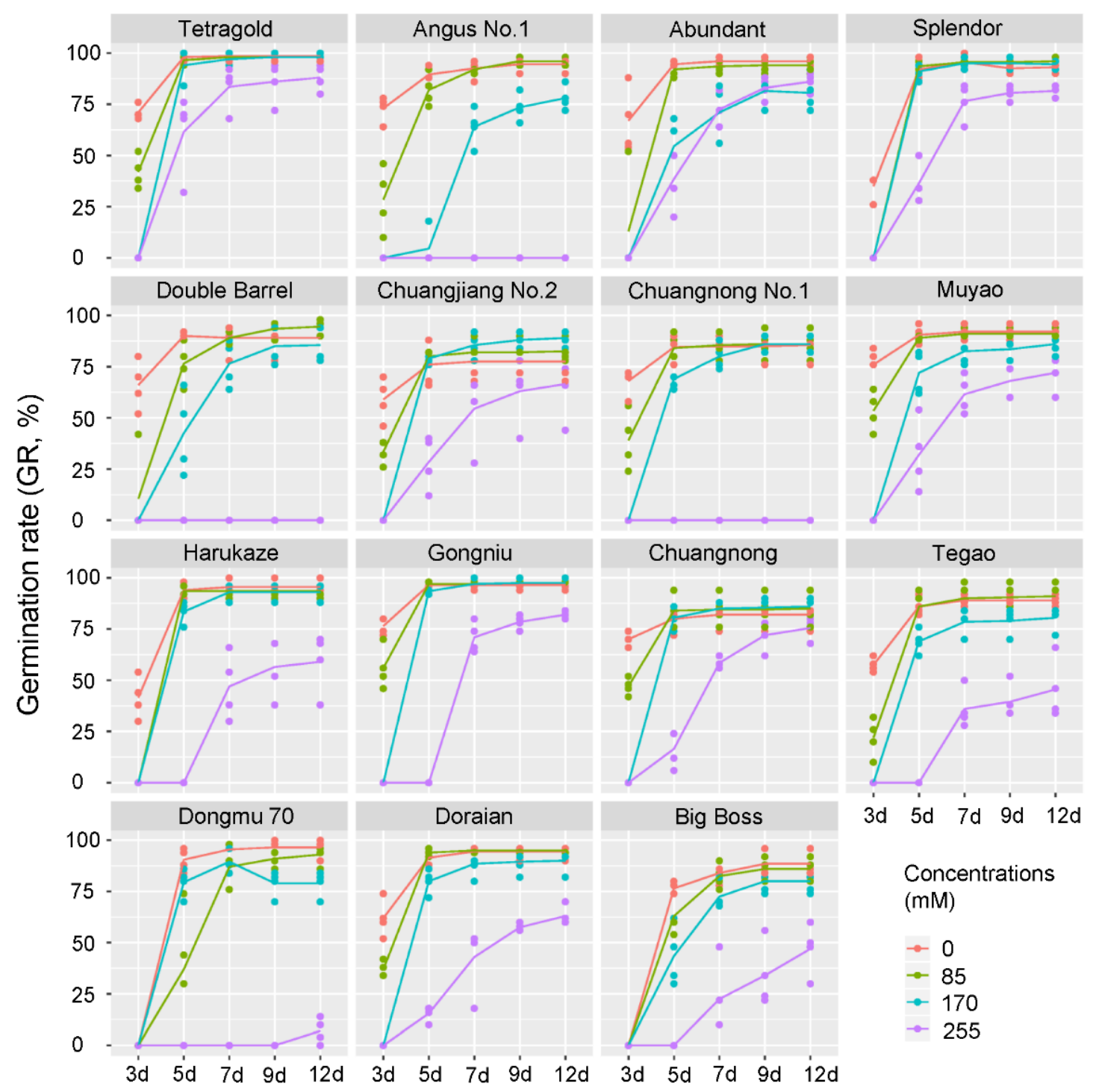

Figure 1. The germination rate (\%) on the $3 \mathrm{rd}, 5 \mathrm{th}, 7 \mathrm{th}, 9 \mathrm{th}$, and 12 th day responses to different $\mathrm{NaCl}$ concentrations in 15 Italian ryegrass cultivars.

The highest relative I and lowest relative GE and GEI were observed in cultivars Angus No. 1 and Double Barrel regardless of $\mathrm{NaCl}$ level (Figure 2b,c). When $\mathrm{NaCl}$ concentration reached $255 \mathrm{mM}$, the maximum values of relative GE and GEI were observed in cultivar Tetragold among the 15 cultivars. The relative GE and GEI in cultivars Angus No. 1, Double Barrel, Chuangnong No. 1, and Dongmu 70 was lower than those in the cultivars under $255 \mathrm{mM} \mathrm{NaCl}$ concentration (Figure 2a,b), while the relative I for those cultivars was nearly 100\% (Figure 2c). 


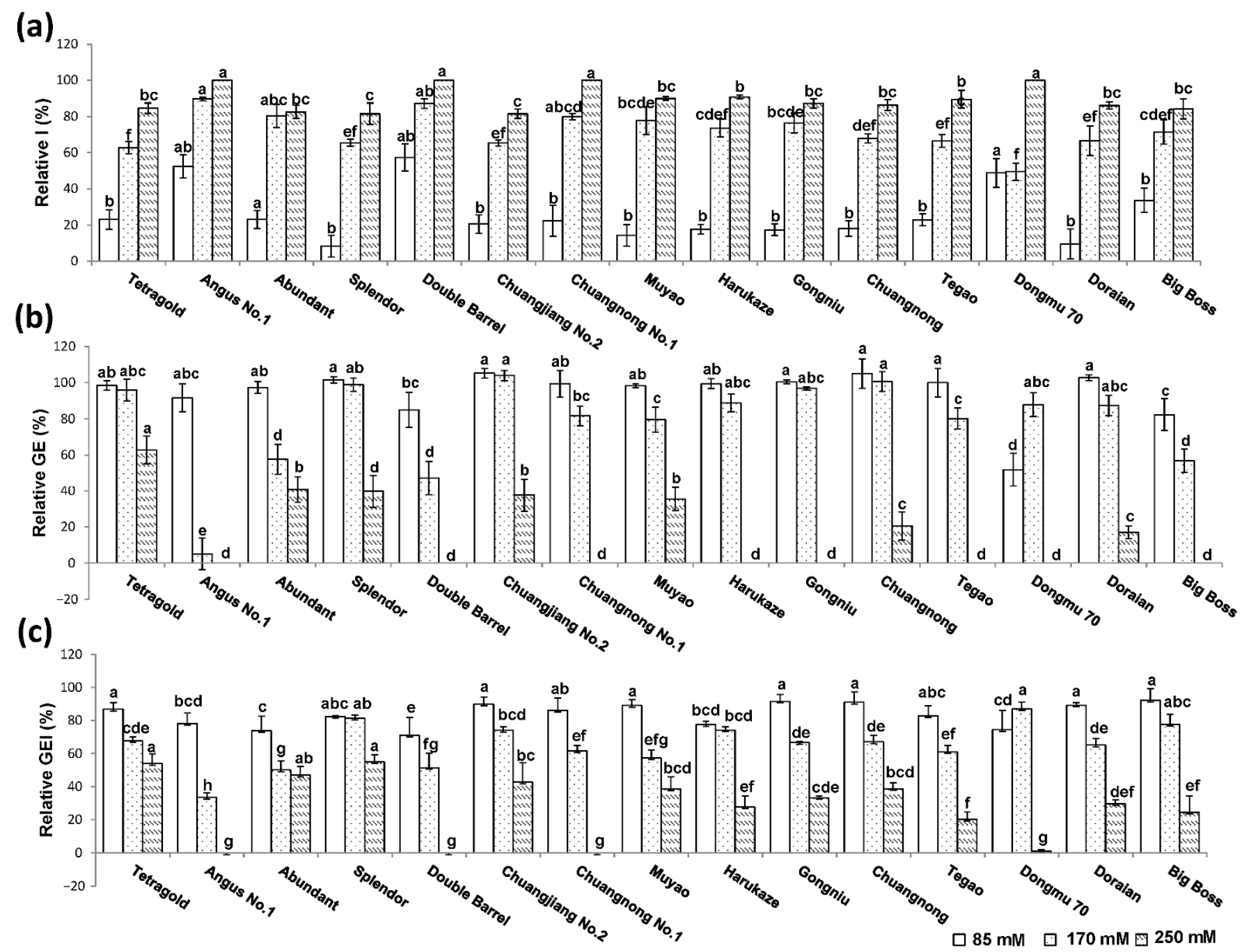

Figure 2. The relative inhibition rate of shoot elongation (I), germination energy (GE), and germination index (GEI) for each cultivar under different $\mathrm{NaCl}$ treatment; (a) relative inhibition rate of shoot elongation response to different $\mathrm{NaCl}$ concentrations in 15 Italian ryegrass cultivars; (b) relative germination energy response to different $\mathrm{NaCl}$ concentrations in 15 Italian ryegrass cultivars; (c) relative germination index response to different $\mathrm{NaCl}$ concentrations in 15 Italian ryegrass cultivars. For a single trait, relative value was the ratio of observed value in treatment relative to the control. Error bars are \pm standard deviation. Columns marked by the same lower-case letters for a given $\mathrm{NaCl}$ concentration are not significant at $p<0.05$ (Tukey's test) for the comparison of different cultivars.

\subsection{Salt Effects and Trait Variation}

To evaluate the injury introduced by salinity exposure, we measured the SI for each cultivar under different $\mathrm{NaCl}$ concentrations (Figure 3). Under the treatment of $100 \mathrm{mM}$ $\mathrm{NaCl}$, the highest SI for SGR (52.8\%) and RGR (28.5\%) were observed in cultivar Tegao (Figure 3a,b). The SI for SGR for cultivars Abundant and Doraian were lower than those in the other assessed cultivars at the $100 \mathrm{mM} \mathrm{NaCl}$ treatment regime. When $\mathrm{NaCl}$ concentration was up to $200 \mathrm{mM}$, cultivar Chuangnong had the lowest SI for SGR and RGR. The minimum SI for Chl was found in cultivars Double Barrel or Chuangnong No. 1 regardless of $\mathrm{NaCl}$ level. The relatively low SI for EL was observed in cultivar Tegao regardless of $\mathrm{NaCl}$ level. The SI for LWC in cultivars Chuangnong No. 1 and Muyao was higher than that of other cultivars, under two $\mathrm{NaCl}$ concentrations. 


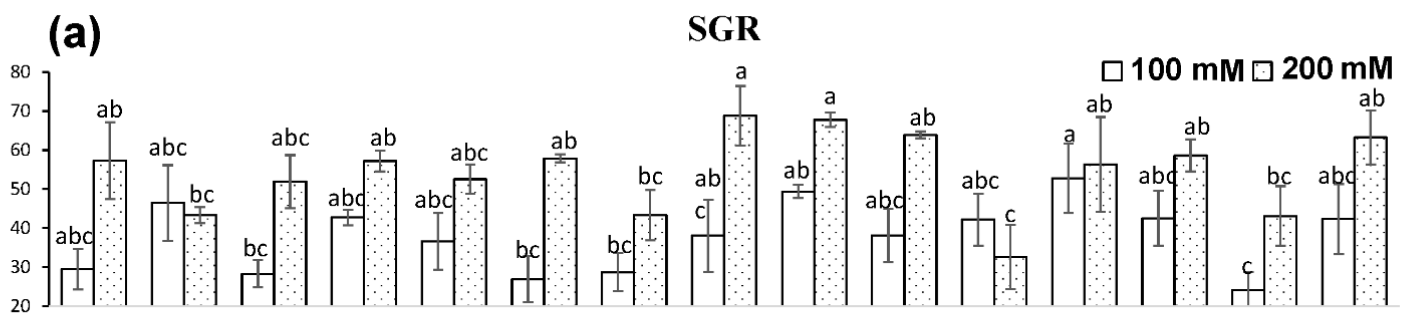

(b)
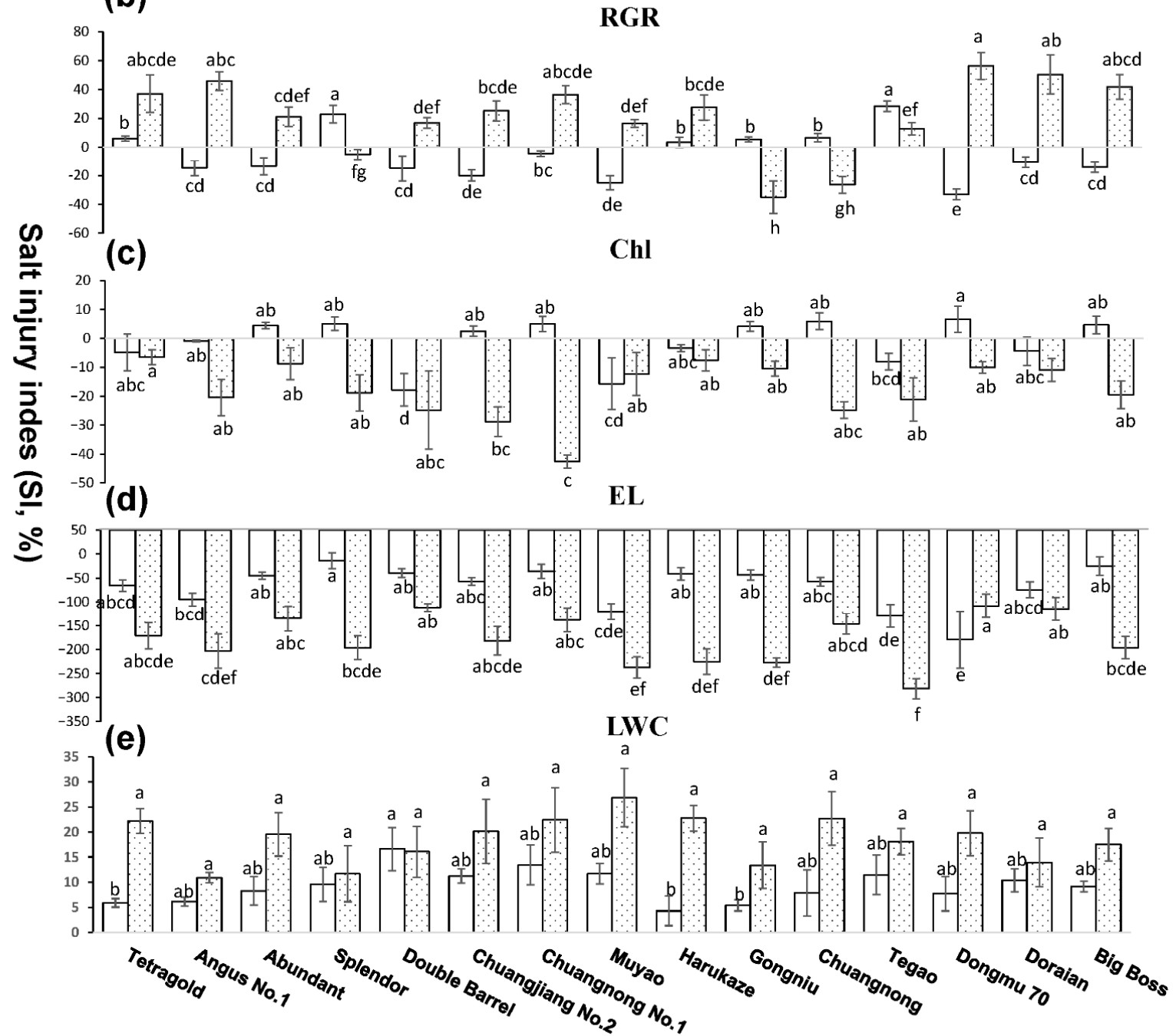

Figure 3. The salt injury index (SI) for each cultivar under different $\mathrm{NaCl}$ treatment; (a) the SI for shoot growth rate (SGR); (b) the SI for root growth rate (RGR); (c) the SI for chlorophyll content (Chl); (d) the SI for electrical conductivity (EL); (e) the SI for leaf relative water content (LWC). Error bars are \pm standard deviation. Columns marked by the same lower-case letters for a given $\mathrm{NaCl}$ concentration are not significant at $p<0.05$ (Tukey's test) for the comparison of different cultivars.

Significant treatment and genotype effects were observed for SGR, RGR, Chl, EL, and GR (Table S1). However, no significant genotype effect on LWC was observed. There was a significant interaction effect between genotype and treatment on RGR, EL, and GR (Table S1). When treated with $200 \mathrm{mM} \mathrm{NaCl}$, the SGR, RGR, and LWC were significantly reduced by $47.5 \%, 46.0 \%$, and $31.2 \%$, respectively. The SGR and LWC were also significantly reduced under $100 \mathrm{mM} \mathrm{NaCl}$ concentration compared to the control, although the reduction was not as large as $200 \mathrm{mM} \mathrm{NaCl}$. However, $100 \mathrm{mM} \mathrm{NaCl}$ significantly increased RGR by $36.6 \%$ compared to the control. The EL was significantly increased by $476.9 \%$ when treated with $200 \mathrm{mM} \mathrm{NaCl}$. In addition, compared with the control, there was no obvious reduction in GR when the seeds were treated with $170 \mathrm{mM} \mathrm{NaCl}$, while $255 \mathrm{mM}$ significantly reduced 
it by $50.1 \%$. Large variations in SGR, RGR, Chl, LWC, EL, and GR values were observed in response to $\mathrm{NaCl}$ treatments among the accessions (Table S2, Figure 3).

The $\mathrm{Na}$ and $\mathrm{K}$ concentrations and $\mathrm{Na} / \mathrm{K}$ ratio for each cultivar is provided in Table 1. The accumulation of $\mathrm{Na}$ in the leaves of 15 cultivars significantly increased, while $\mathrm{K}$ concentration significantly decreased under $\mathrm{NaCl}$ treatment. Salt treatment significantly increased the $\mathrm{Na} / \mathrm{K}$ ratio in the leaves of the 15 assessed cultivars as compared to the control. The Na/K ratio in cultivars Harukaze, Tegao, Doraian, and Chuangnong was higher than that of other cultivars under $\mathrm{NaCl}$ treatment. The remaining other cultivars had a similar $\mathrm{Na} / \mathrm{K}$ ratio.

Table 1. The $\mathrm{Na}$ and $\mathrm{K}$ concentrations and $\mathrm{Na} / \mathrm{K}$ ratio in the shoot for each cultivar under control (CK) and $200 \mathrm{mM} \mathrm{NaCl}$ treatment (salt).

\begin{tabular}{|c|c|c|c|c|c|c|}
\hline \multirow{2}{*}{ Cultivar } & \multicolumn{6}{|c|}{$\mathrm{Na}\left(\mathrm{mg} \mathrm{kg}^{-1}, \mathrm{DW}\right) \mathrm{K}\left(\mathrm{mg} \mathrm{kg}^{-1}, \mathrm{DW}\right) \mathrm{Na} / \mathrm{K}$} \\
\hline & CK & Salt & CK & Salt & CK & Salt \\
\hline Tetragold & $12.28 \mathrm{bc}$ & $30.29 c$ & 90.19 bc & $52.94 \mathrm{bc}$ & $0.14 \mathrm{a}$ & $0.58 \mathrm{bc}$ \\
\hline Angus No. 1 & $12.08 \mathrm{bc}$ & $31.34 \mathrm{c}$ & $84.00 \mathrm{c}$ & $56.24 \mathrm{bc}$ & $0.15 \mathrm{a}$ & $0.58 \mathrm{bc}$ \\
\hline Abundant & $13.54 \mathrm{ab}$ & $32.86 \mathrm{bc}$ & $82.12 \mathrm{c}$ & $60.57 \mathrm{~b}$ & $0.17 \mathrm{a}$ & $0.55 \mathrm{c}$ \\
\hline Splendor & $12.80 \mathrm{bc}$ & $36.51 \mathrm{ab}$ & $97.65 \mathrm{a}$ & $58.76 \mathrm{~b}$ & $0.13 \mathrm{a}$ & $0.61 \mathrm{bc}$ \\
\hline Double Barrel & $12.82 \mathrm{bc}$ & $41.45 \mathrm{a}$ & $102.61 \mathrm{a}$ & $71.74 \mathrm{a}$ & $0.13 \mathrm{a}$ & $0.57 \mathrm{bc}$ \\
\hline Changjiang No. 2 & $18.35 \mathrm{a}$ & $29.27 \mathrm{c}$ & $79.00 \mathrm{~cd}$ & $50.63 \mathrm{bc}$ & $0.24 \mathrm{a}$ & $0.57 \mathrm{bc}$ \\
\hline Chuangnong No. 1 & $13.24 \mathrm{bc}$ & $31.03 c$ & $85.44 \mathrm{c}$ & $54.27 \mathrm{bc}$ & $0.16 \mathrm{a}$ & $0.57 \mathrm{bc}$ \\
\hline Muyao & $14.36 \mathrm{ab}$ & $33.03 \mathrm{bc}$ & $82.03 c$ & $53.79 \mathrm{bc}$ & $0.18 \mathrm{a}$ & $0.59 \mathrm{bc}$ \\
\hline Harukaze & $14.08 \mathrm{ab}$ & $41.42 \mathrm{a}$ & $92.01 \mathrm{~b}$ & $57.36 \mathrm{bc}$ & $0.15 \mathrm{a}$ & $0.72 \mathrm{a}$ \\
\hline Gongniu & $11.98 \mathrm{bc}$ & $30.18 c$ & $87.40 \mathrm{bc}$ & $55.75 \mathrm{bc}$ & $0.14 \mathrm{a}$ & $0.55 \mathrm{bc}$ \\
\hline Chuangnong & $12.95 \mathrm{bc}$ & $39.11 \mathrm{a}$ & $94.39 \mathrm{ab}$ & $56.06 \mathrm{bc}$ & $0.14 \mathrm{a}$ & $0.70 \mathrm{a}$ \\
\hline Tegao & $8.63 c$ & $33.69 \mathrm{bc}$ & $61.41 \mathrm{~d}$ & $49.01 \mathrm{bc}$ & $0.14 \mathrm{a}$ & $0.67 \mathrm{ab}$ \\
\hline Dongmu 70 & $12.28 \mathrm{bc}$ & $33.76 \mathrm{bc}$ & $87.78 \mathrm{bc}$ & $55.01 \mathrm{bc}$ & $0.14 \mathrm{a}$ & $0.60 \mathrm{bc}$ \\
\hline Doraian & $11.24 \mathrm{bc}$ & $30.57 \mathrm{c}$ & $76.16 \mathrm{~cd}$ & 44.92 c & $0.15 \mathrm{a}$ & $0.68 \mathrm{ab}$ \\
\hline Big Boss & $12.93 \mathrm{bc}$ & $30.67 c$ & $97.00 \mathrm{a}$ & $56.23 \mathrm{bc}$ & $0.14 \mathrm{a}$ & $0.55 \mathrm{bc}$ \\
\hline
\end{tabular}

Means marked by the same lower-case letters are not significant at 0.05 (Tukey's test) for the comparison of different cultivars at a given treatment.

\subsection{Evaluation and Cluster Analysis of Salt Tolerance in Cultivars of Italian Ryegrass}

To further evaluate the salt tolerance of the 15 assessed cultivars, the subordinate function value, index weights, and D were calculated (Table 2). Based on our data described above, the effects of salt stress on different traits varied markedly under $200 \mathrm{mM} \mathrm{NaCl}$ concentration (Table S2). In addition, $255 \mathrm{mM} \mathrm{NaCl}$ stress led to a high significant difference in GR among 15 Italian ryegrass cultivars (Table S2). Therefore, the subordinate function value of the SGR, RGR, Chl, EL, and LWC under $200 \mathrm{mM} \mathrm{NaCl}$ concentration and the GR under $255 \mathrm{mM} \mathrm{NaCl}$ concentration was used to evaluate salt tolerance of different cultivars. The values of $W j$ in RGR, Chl, and GR were higher than that of the other parameters. The sum of these three weights was more than $70 \%$ of the total weights, indicating that the indexes of RGR, Chl, and GR might be used as key indexes in the evaluation system. The minimum amount of $W j$ was found in SGR, LWC, and EL. According to the D value, the trend of salt tolerance among the 15 cultivars was as follows: Gongniu > Chuangnong > Splendor $>$ Abundant $>$ Tetragold $>$ Muyao $>$ Doraian $>$ Chuangjiang No. 2, Harukaze, Tegao $>$ Double Barrel $>$ Big Boss $>$ Dongmu $70>$ Angus No. $1>$ Chuangnong No. 1, suggesting that Gongniu has the highest salt tolerance and Chuangnong No. 1 has the lowest tolerance to salt stress. 
Table 2. The values of the subordinate function, integrated value (D), and order of each cultivar under salt stress. SGR means shoot growth rate, RGR means root growth rate, Chl means chlorophyll content, LWC means leaf relative water content, EL means electrical conductivity, GR means germination rate (on the 12th day) and $W j$ is the weighted coefficient.

\begin{tabular}{|c|c|c|c|c|c|c|c|c|}
\hline \multirow{2}{*}{ Cultivar } & \multicolumn{8}{|c|}{ Subordinate Function Value of Different Cultivars } \\
\hline & SGR & RGR & Chl & LWC & EL & GR & $\mathbf{D}$ & Order \\
\hline Tetragold & 0.68 & 0.80 & 0.24 & 0.71 & 0.35 & 0.00 & 0.50 & 5 \\
\hline Angus No. 1 & 0.57 & 0.90 & 0.42 & 0.55 & 0.55 & 1.00 & 0.76 & 14 \\
\hline Abundant & 0.53 & 0.58 & 0.00 & 0.00 & 0.16 & 0.11 & 0.30 & 4 \\
\hline Splendor & 0.68 & 0.28 & 0.38 & 0.06 & 0.51 & 0.06 & 0.29 & 3 \\
\hline Double Barrel & 0.55 & 0.56 & 0.54 & 0.34 & 0.02 & 1.00 & 0.57 & 11 \\
\hline Changjiang No. 2 & 0.70 & 0.67 & 0.64 & 0.59 & 0.43 & 0.17 & 0.55 & 8 \\
\hline Chuangnong No. 1 & 0.30 & 0.76 & 1.00 & 0.73 & 0.17 & 1.00 & 0.77 & 15 \\
\hline Muyao & 1.00 & 0.54 & 0.21 & 1.00 & 0.75 & 0.21 & 0.51 & 6 \\
\hline Harukaze & 0.97 & 0.67 & 0.09 & 0.75 & 0.68 & 0.42 & 0.55 & 8 \\
\hline Gongniu & 0.86 & 0.00 & 0.16 & 0.18 & 0.69 & 0.13 & 0.19 & 1 \\
\hline Chuangnong & 0.00 & 0.10 & 0.53 & 0.41 & 0.22 & 0.16 & 0.22 & 2 \\
\hline Tegao & 0.66 & 0.50 & 0.44 & 0.47 & 1.00 & 0.52 & 0.55 & 8 \\
\hline Dongmu 70 & 0.72 & 1.00 & 0.15 & 0.57 & 0.00 & 1.00 & 0.71 & 13 \\
\hline Doraian & 0.29 & 0.91 & 0.17 & 0.22 & 0.04 & 0.46 & 0.52 & 7 \\
\hline Big Boss & 0.85 & 0.86 & 0.40 & 0.43 & 0.51 & 0.68 & 0.68 & 12 \\
\hline$W j$ & 0.06 & 0.40 & 0.18 & 0.08 & 0.10 & 0.19 & & \\
\hline
\end{tabular}

Cluster analysis of tolerance was performed among the cultivars, which was based on their D values. Thus, 15 Italian ryegrass cultivars were clustered into three groups at a squared Euclidean distance of 5 (Figure S2). Cultivars Gongniu, Chuangnong, Splendor, and Abundant were clustered in group I, with salt tolerance. Four cultivars were in group II, including Big Boss, Dongmu, Angus No. 1, and Chuangnong No. 1, with low salt tolerance. Others were clustered in group III, with medium salt tolerance.

\subsection{Forage Quality of Italian Ryegrass under Salt Stress}

To determine the effect of $\mathrm{NaCl}$ on forage quality, the metrics of $\mathrm{CP}, \mathrm{CF}, \mathrm{ADF}, \mathrm{NDF}$, CA, and WSS were analyzed. As shown in Figure 4, NaCl-treatment did not significantly alter $\mathrm{CP}, \mathrm{CF}$, and WSS for most cultivars in comparison to the control. As expected, the $\mathrm{CP}$ in cultivars Angus No. 1, Muyao, Tegao, and Dongmu 70, were significantly reduced under $\mathrm{NaCl}$ treatment. The $\mathrm{CF}$ in cultivars Abundant, Chuangnong No. 1, and Chuangnong and the WSS in cultivar Chuangnong were significantly increased under $\mathrm{NaCl}$ treatment. Generally, salt stress decreased the content of ADF and NDF, but increased CA content, compared to the control. As a result, a significant increase in GI for most cultivars was observed under the $\mathrm{NaCl}$ treatment. The GI in cultivars Tetragold, Abundant, Splendor, Harukaze, Gongniu, Chuangnong, and Doraian were significantly increased by $44.5 \%, 34.9 \%, 52.5 \%, 36.5 \%, 37.5 \%, 44.6 \%$, and $46.7 \%$, respectively. A significant positive correlation was found between CP and D, and CF and SGR, whereas CA was negatively correlated with SGR and D. Furthermore, ADF was determined to show a significant negative correlation, and GI showed a significant positive correlation to GR (Table S3). 
(a) $\mathrm{CP}$

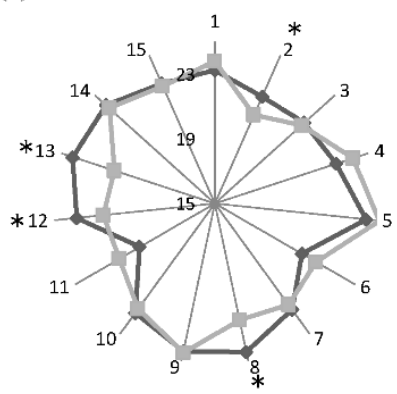

(d)

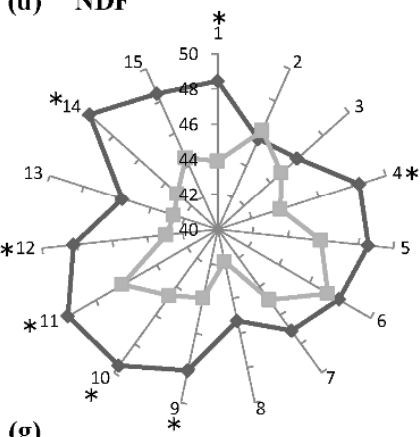

(g) 80 GI (b)

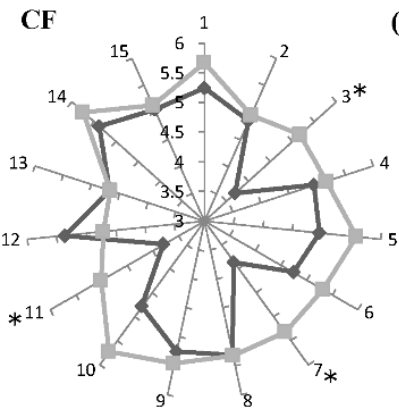

(e)

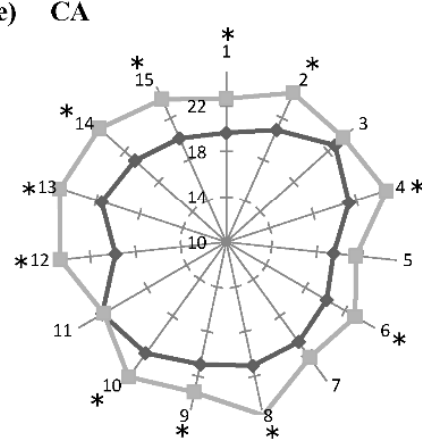

(c)

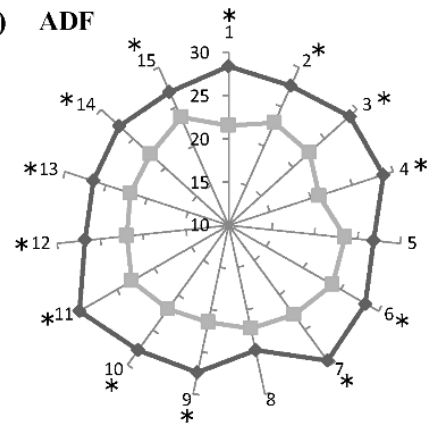

(f) WSS

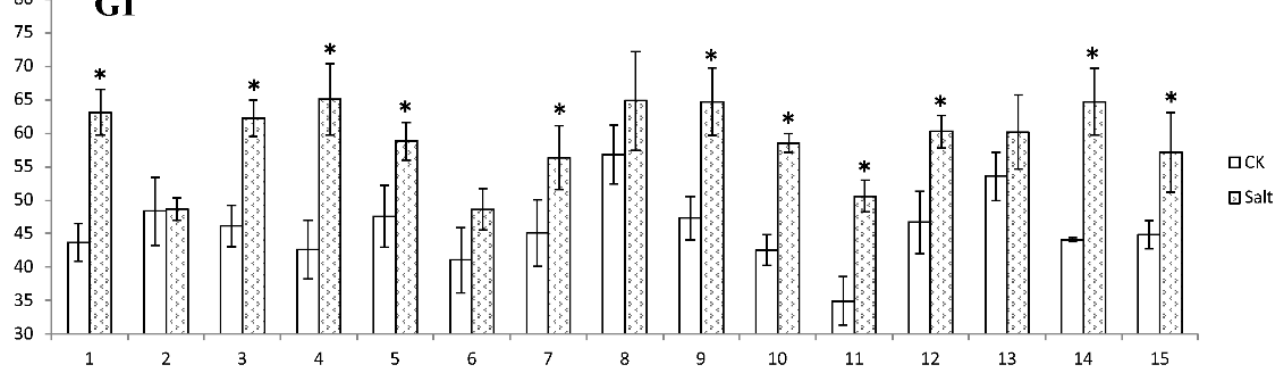

Figure 4. Effect of salt on the forage quality of Italian ryegrass; (a) crude protein (CP); (b) crude fat (CF); (c) acid detergent fiber (ADF); (d) neutral detergent fiber (NDF); (e) crude ash (CA); (f) water-soluble carbohydrate (WSS); and (g) grading index (GI). Error bars are \pm standard deviation. Asterisk means significantly different between control (CK) and salt stress (Salt) at the 0.05 level. The numbers from 1 to 15 indicate cultivars Tetragold, Angus No. 1, Abundant, Splendor, Double Barrel, Chuangjiang No. 2, Chuangnong No. 1, Muyao, Harukaze, Gongniu, Chuangnong, Tegao, Dongmu 70, Doraian, and Big Boss, respectively.

\subsection{Gene Expression Alteration in Salt Stress-Sensitive and Tolerant Cultivars}

To understand the gene expression differences between salinity stress-sensitive and tolerant cultivars, we profiled gene expression by RNA-seq before and after salinity stress using cultivar Abundant as the stress-tolerant and Angus No. 1 as the stress-sensitive cultivars. RNA-seq data analysis revealed differential gene expression in both cultivars after being exposed to salinity stress and there were remarkable differences in gene expression after salinity stress between the two assessed cultivars (Figure 5). There were more differentially expressed genes (DEGs) in the tolerant cultivar than in the sensitive cultivar. Moreover, most DEGs detected in sensitive cultivar Angus No. 1 were also differentially expressed in the tolerant cultivar (Figure $5 a, b$ ). Hierarchy clustering analysis of all DEGs found in both cultivars showed that, although there was a significant difference in the number of DEGs, both cultivars exhibit a similar response pattern to salinity stress as the samples were clustered into groups by their treatment condition rather than their genetic background (Figure 5c). Furthermore, we performed GO enrichment analysis for DEGs in both cultivars and the results showed that their biological response to salinity stress is similar, although their phenotypes differed under salinity stress. We found that the genes that respond to water deficiency, abiotic stress, and oxidant reduction were remarkably 
altered (Figure 6). Furthermore, the expression of genes that participate in photosystem regulation and carbohydrate metabolism were largely down-regulated. These findings are in line with our physical measurements. Cation/ion bindings capacity are critical for plants to survive under salinity stress [11]. To explore the possible gene expression differences between two cultivars, we further compared the GO terms that were enriched under salinity stress (Figure $6 \mathrm{~b}$ ) and this analysis showed that genes associated with the functions of cation/ion binding are more significantly enriched in DEGs identified in cultivar Abundant. The differences in GO terms enrichment may imply a different tolerance to salinity stress between the two cultivars.

(a)

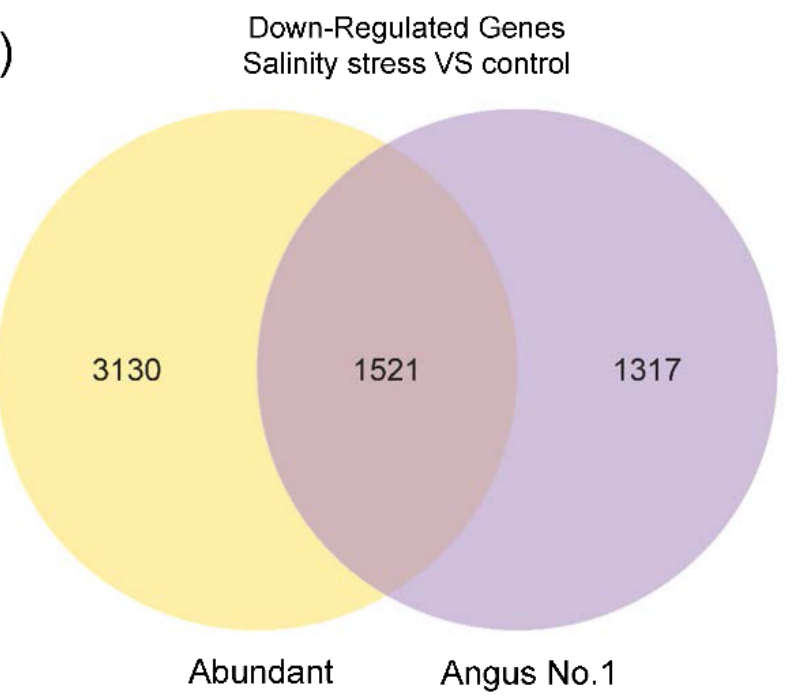

(b)

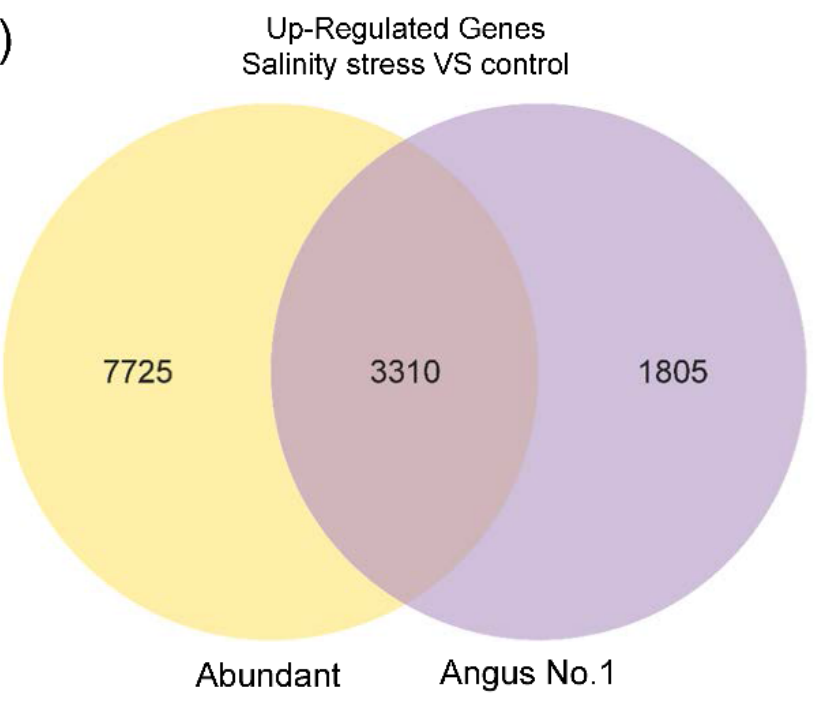

(c)
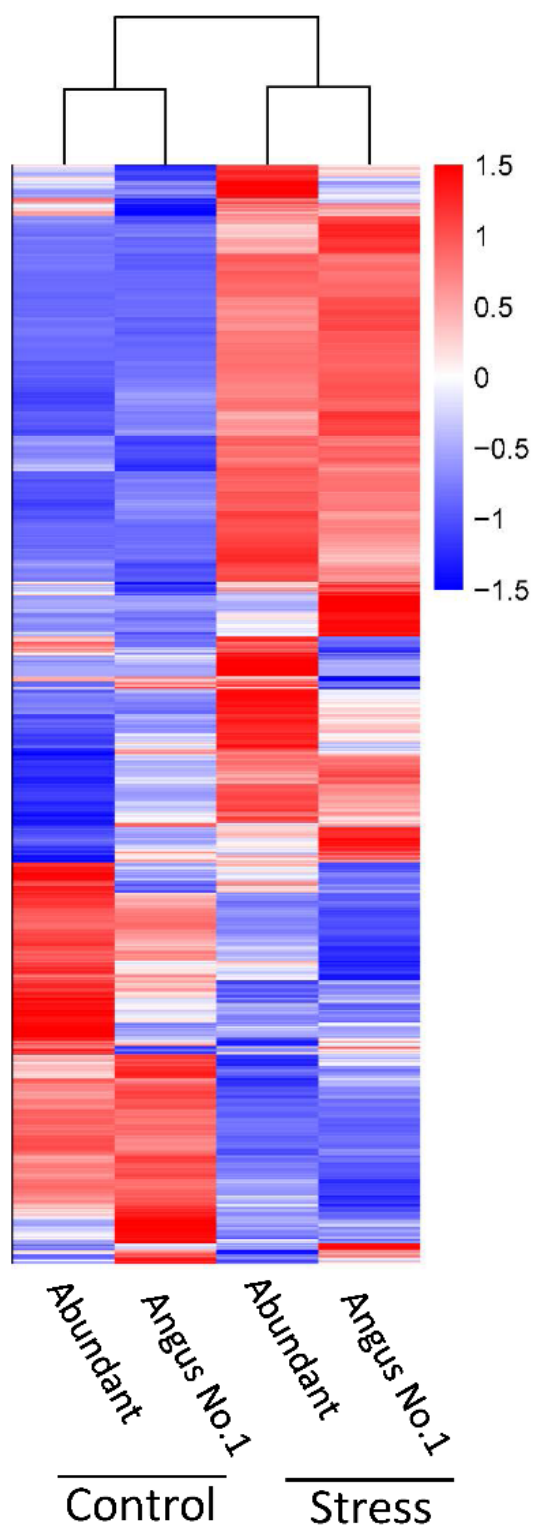

Figure 5. Comparison of differentially expressed genes in stress-tolerant and sensitive cultivars; (a) overlaps of downregulated genes between cultivars Abundant and Angus No. 1 during salinity stress; (b) overlaps of up-regulated genes between cultivars Abundant and Angus No. 1 during salinity stress; and (c) clustering results of all DEGs in two cultivars that show cluster patterns of treatment conditions. 
(a)
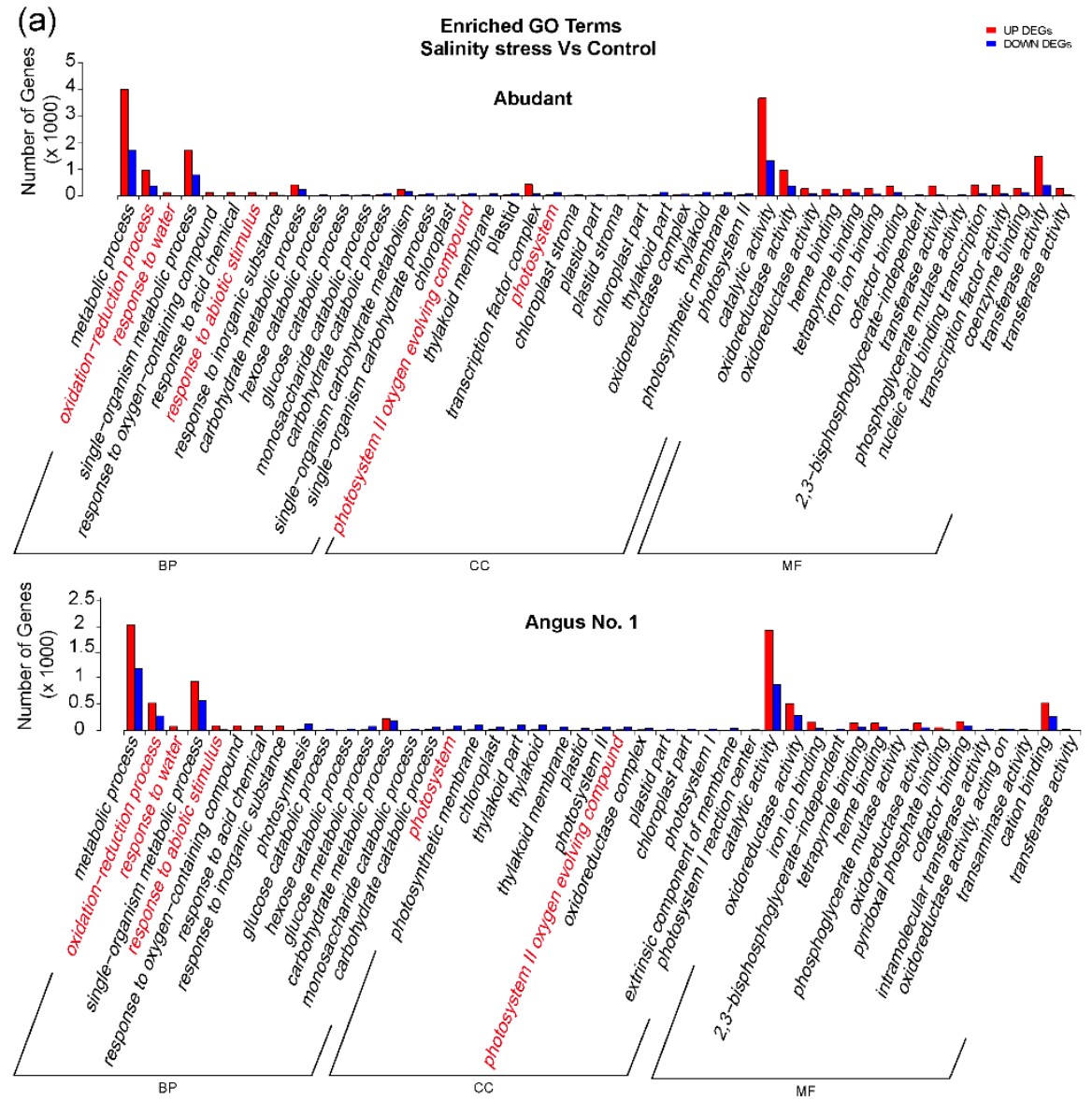

(b)

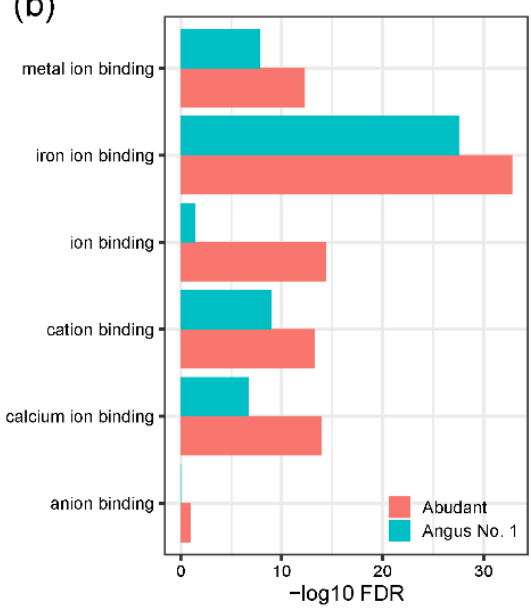

Figure 6. Gene Ontology enrichment analysis of differentially expressed genes; (a) bar plot of Gene Ontology enrichments for cultivar Abundant (top panel) and Angus No. 1 (bottom panel) for Up and Down DEGs respectively; and (b) comparison of ion binding related GO terms between cultivars under salinity stress.

\section{Discussion}

Many biological processes in plants are affected by salt stress [18]. In particular, different cultivars showed significant differences in growth parameters under saline conditions. It was reported that salt tolerance in early growth stages is not always related to that in mature stages [11]. Different salt tolerance at different growth stages has been observed in many species, such as corn (Zea mays L.), rice (Oryza sativa), and cowpeas (Vigna unguiculata L.) [11,33-35]. For Italian ryegrass, it was found that the $\mathrm{NaCl}$ tolerance during vegetative growth was lower than perennial ryegrasses (Lolium perenne cv. Vic. Cert.) and Wimmera ryegrass (Lolium rigidum) in contrast to the results of the germination experiment [7]. This finding suggests the need for assessment of salt tolerance at different stages of development in a screening program to understand salt tolerance. Therefore, in this study, cultivars were evaluated for salt tolerance at different developmental stages.

Seed germination is the beginning of plant life. When salt-sensitive cultivars were planted in saline soils, the germination rate was significantly inhibited and this led to low plant density and low yields $[1,36]$. In this study, the GR for most cultivars was significantly reduced, but still maintained $50 \%$ germination at the very high $\mathrm{NaCl}$ concentration (255 mM), thus indicating that the threshold for impaired germination was $255 \mathrm{mM}$ for Italian ryegrass. This threshold was higher than Marcar and Li [7,9], who reported that the threshold for impaired germination was $200 \mathrm{mM}$ and $150 \mathrm{mM}$, respectively. Among the 15 Italian ryegrass cultivars, 5 cultivars displayed salt tolerance (including Tetragold, Abundant, Splendor, Chuangnong, and Tegao), 6 cultivars displayed moderate salt tolerance, and 4 cultivars displayed salt sensitivity (including Angus No. 1, Double Barrel, 
Chuangnong No. 1, and Doraian) during the germination stage. Moreover, the GEI and GE reflect the seed germination ability. For GE and GEI, the decrease in most of the 15 cultivars was less than $50 \%$ under the $255 \mathrm{mM} \mathrm{NaCl}$ treatment. These results indicated that GE and GEI under $255 \mathrm{mM} \mathrm{NaCl}$ treatment could be used as one of the most reliable indicators for salt tolerance screening in Italian ryegrass during the germination stage.

Root and shoot growth reduction are common responses to salt stress [13]. Our results indicated that SGR of Italian ryegrass is more sensitive and RGR is less affected or even stimulated by salt stress (Table S1). It seems that the need to find deeper nutrients and water exceeds the need to increase the shoot growth for photosynthetic carbon gain under salinity. Munns and Tester have reported that a reduction in leaf area development relative to root growth would decrease the water use, thus allowing it to conserve moisture taken up from the soil and prevent an escalation in the salt concentration in plant cells [2]. Previous research indicated that the reduction in shoot growth rate was associated with the increasing $\mathrm{Na}, \mathrm{Na} / \mathrm{K}$ ratio, and reduction of $\mathrm{K}$ under salt stress [25]. Our results suggested that growth inhibition could be related to the osmotic and ionic effects (nutritional deficiency and/or imbalance). Interestingly, when treated with $200 \mathrm{mM} \mathrm{NaCl}$, the Chl was significantly increased by $7.4 \%$ compared with the control. This paradox is explained by the changes in cell anatomy that give rise to smaller, thicker leaves and result in a higher chloroplast density per unit leaf area [2].

In general, salt stress may cause a series of phenotypic, physiological, and biochemical changes in plants. However, not all parameters have the same contribution to salt tolerance, hence the use of a single index to evaluate salt tolerance would be biased. In conventional salt tolerance breeding, the lack of a suitable and reliable evaluation index of salt tolerance is one of the reasons for the limited success [11]. Therefore, it is necessary to identify a reliable evaluation index to determine the salt tolerance of Italian ryegrass during the different developmental stages. In this study, the sum of $W j$ in RGR, Chl, and GR was more than $70 \%$ of the total weights. These results indicated that these three traits might be useful as key indexes in the evaluation system for the identification of salt-resistant cultivars of Italian ryegrass. Previous research combined with our results show that the D value is a better index on the evaluation of salt tolerance [30]. In the study, a cluster analysis was used based on the D value to facilitate the evaluation of salt tolerance among cultivars. It was clearly shown in the present study that all the cultivars could be grouped into three groups. The group I including Gongniu, Chuangnong, Splendor, and Abundant, with salt tolerance may be a good set of materials to be cultivated in saline land.

A favorable combination of salt tolerance at the germination stage and vegetative growth stages was identified in Chuangnong, Splendor, and Abundant with these three cultivars possessing a good germination rate. Our research suggests that Chuangnong, Splendor, and Abundant should be introduced in a crossbreeding program as elite salttolerant cultivars to incorporate different desirable agronomic traits. The other cultivars were either less tolerant or failed to display a favorable combination of salt tolerance characteristics at different growth stages.

High forage yield along with salt tolerance is important for forage for livestock. Salt stress could also impair forage quality [37]. CP content of forage grass is a vital criterion for quality evaluation [38]. Impaired protein synthesis under salt stress conditions by other grass species has previously been reported by many investigators [14,37]. While the effect of salinity on CP content of Italian ryegrass in the current study was not consistent with previous research, $200 \mathrm{mM} \mathrm{NaCl}$ treatment did not significantly alter CP in comparison to the control for most cultivars. ADF and NDF are other important quality characteristics for forage grasses [39]. The intake and digestibility of plant vegetative biomass will generally increase with the decrease of NDF and ADF percentages. Considerable reduction in NDF and ADF percentages of Italian ryegrass under saline conditions in our study indicates more intake and digestibility of forage grass by the animal. The higher CP and lower NDF and ADF contents of the Italian ryegrass under salinity in this study, compared to the control, could be due to the stage of maturity of grasses at harvest, as maturity is one of 
the major factors influencing forage quality [37]. A similar trend was observed for the GI which was much higher under salinity than in the control. The GI is also used to predict the voluntary intake of available energy of the forages [20]. The forage grass is considered superior and first level when the GI value > 53.68 and 33.51 < GI < 53.68, respectively. In the present study, the GI value was higher than 53.68 in cultivar Muyao under control conditions. However, the GI value was higher than 60.00 in cultivars Tetragold, Abundant, Splendor, Muyao, Harukaze, Tegao, Dongmu 70, and Doraian under salt stress. These cultivars were identified as high forage quality under salt stress.

Gene expression analysis by RNA-seq revealed that cultivars of different salinity tolerance capacities shared certain degrees of similarity in their molecular response to stress, compared to their corresponding controls. We also noted that genes involved in photosystem and carbohydrate synthesis were affected by salinity stress according to their GO enrichments. We suggest that the enrichment of these specific gene cohorts is due to the water supply deficiency which slows down the reactions in photosystem and carbohydrate processes. Combining RNA-seq results with our physiological indices measurements, we believe that our findings provide a highly useful resource in salinity-tolerant ryegrass screening.

\section{Conclusions}

In conclusion, the 15 Italian ryegrass cultivars performed differently in terms of GR under $255 \mathrm{mM} \mathrm{NaCl}$ treatment, indicating that the threshold for impaired germination was $255 \mathrm{mM}$. Salt tolerance of Italian ryegrass cultivars was evaluated objectively by subordinate function and standard deviation coefficient methods. Three parameters, RGR, Chl, and GR, provided insightful metrics in determining salt tolerance. Not only based on those parameters but also the D value, Gongniu, Chuangnong, Splendor, and Abundant were identified as the most tolerant cultivars. However, based on combined attributes at the germination and vegetative growth stages, Gongniu, Chuangnong, Splendor, and Abundant emerged the most tolerant of the 15 cultivars assessed. The method demonstrated in this study, i.e., cluster group ranking of cultivars based on multiple characters and D value, can be applied in salt-tolerance breeding to evaluate salt tolerance among cultivars with great advantage over conventional methods. In addition, the constant CP and lower NDF and ADF contents of the Italian ryegrass were observed under salinity, compared to the control. Together, these assessments indicate that the intake and digestibility of Italian ryegrass under salinity are higher compared to the control. Combining CP and GI value, the cultivar Tetragold, Abundant, Splendor, Muyao, Harukaze, Tegao, Dongmu 70, and Doraian were identified as high forage quality under salt stress. Based on these findings, we conclude that Splendor and Abundant emerge as the ideal candidates based on combined attributes related to germination, salt tolerance, and overall forage quality.

Supplementary Materials: The following are available online at https: / www.mdpi.com/article / 10.3390/agronomy11081487/s1, Figure S1: Repeated measures analysis of seed germination rate response to $\mathrm{NaCl}$ concentration in different periods. Comparisons between different concentrations within accession were performed with a paired $t$-test and $p$-value was adjusted by the Bonferroni method. The numbers from 1 to 15 indicated cultivars Tetragold, Angus No. 1, Abundant, Splendor, Double Barrel, Chuangjiang No. 2, Chuangnong No. 1, Muyao, Harukaze, Gongniu, Chuangnong, Tegao, Dongmu 70, Doraian, and Big Boss respectively. ${ }^{\prime * \prime}: p<0.05 ;{ }^{\prime * * \prime}: p<0.01$; $^{\prime * * *^{\prime}:} p<0.001$; ‘****': $p<0.0001$. Figure S2: Cluster analysis of 15 Italian ryegrass cultivars based on integrated value (D). Table S1: Analysis of variances with mean squares and treatment significance levels. Table S2: Range of shoot growth rate (SGR), root growth rate (RGR), chlorophyll content (Chl), leaf relative water content (LWC), electrical conductivity (EL), and germination rate (GR, on the 12th day) for 15 cultivars of Italian ryegrass under control (CK) and $\mathrm{NaCl}$ treatment. Table S3: Correlation analysis of the shoot growth rate (SGR), root growth rate (RGR), chlorophyll content (Chl), leaf relative water content (LWC), and electrical conductivity (EL) under $200 \mathrm{mM} \mathrm{NaCl}$ stress and germination rate (GR, on the 12th day) under $255 \mathrm{mM} \mathrm{NaCl}$ stress with the crude protein $(\mathrm{CP})$, crude fat $(\mathrm{CF})$, crude ash 
(CA), neutral detergent fiber (NDF), acid detergent fiber (ADF), water-soluble carbohydrate (WSC), and grading index (GI) of 15 Italian ryegrass cultivars.

Author Contributions: Conceptualization, Y.X., J.F. and X.S.; methodology, Y.X.; software, H.Y. and Y.H.; validation, Y.X. and L.C.; investigation, X.L. (Xiaoning Li) and X.L. (Xiaoying Liu); resources, Y.X., J.F. and X.S.; data curation, Y.X.; writing-original draft preparation, Y.X.; writing-review and editing, X.L. (Xiaoying Liu), M.A., H.Y. and Y.H.; visualization, Y.X.; supervision, J.F. and X.S.; project administration, L.C. and J.F. All authors have read and agreed to the published version of the manuscript.

Funding: This research was funded by the key research and development program of Jiangxi province (grant number: 20171BBG70047), excellent young talents funding plan of Jiangxi province (grant number: 20192BCB23026), and 'Thousand Talents Plan' of Jiangxi province (grant number: jxsq2019201086).

Institutional Review Board Statement: Not applicable.

Informed Consent Statement: Not applicable.

Data Availability Statement: The data presented in this study are available on request from the corresponding author. The data are not publicly available due to privacy.

Conflicts of Interest: The authors declare no conflict of interest.

\section{References}

1. Ding, T.; Yang, Z.; Wei, X.; Yuan, F.; Yin, S.; Wang, B. Evaluation of salt-tolerant germplasm and screening of the salt-tolerance traits of sweet sorghum in the germination stage. Funct. Plant Biol. 2018, 45, 1073-1081. [CrossRef] [PubMed]

2. Munns, R.; Tester, M. Mechanisms of salinity tolerance. Annu. Rev. Plant Biol. 2008, 59, 651-681. [CrossRef] [PubMed]

3. Song, J.; Wang, B. Using euhalophytes to understand salt tolerance and to develop saline agriculture: Suaeda salsa as a promising model. Ann. Bot. 2015, 115, 541. [CrossRef]

4. Johnson, D.W.; Smith, S.E.; Dobrenz, A.K. Genetic and phenotypic relationships in response to $\mathrm{NaCl}$ at different developmental stages in alfalfa. Theor. Appl. Genet. 1992, 83, 833-838. [CrossRef] [PubMed]

5. Li, M.; Sheng, G.P.; Wu, Y.J.; Yu, Z.L.; Bañuelos, G.S.; Yu, H.Q. Enhancement of nitrogen and phosphorus removal from eutrophic water by economic plant annual ryegrass (Lolium multiflorum) with ion implantation. Environ. Sci. Pollut. Res. 2014, 21, 9617-9625. [CrossRef]

6. Beddows, A.R. Lolium Multiflorum Lam. J. Ecol. 1973, 61, 587-600. [CrossRef]

7. Marcar, N.E. Salt tolerance in the genus Lolium (ryegrass) during germination and growth. Aust. J. Agric. Res. 1987, 38, 297-307. [CrossRef]

8. Alonso, S.I.; Guma, I.R.; Clausen, A.M. Variability for salt tolerance during germination in Lolium multiflorum Lam. naturalized in the pampean grasslands. Genet. Resour. Crop Evol. 1999, 46, 87-94. [CrossRef]

9. Li, K.C.; Jiangyun, H.; Lu, X.S. Salt tolerance evaluation of 10 varieties of Lolium multiflorum Lam. at germination period. Acta Agrestia Sin. 2010, 18, 388-398.

10. Zhang, Z.X.; Liu, P.; Yang, Z.Y. Salt tolerance of 25 Lolium perenne varieties at germination stage. Pratacultural Sci. 2007, 24, 14-19.

11. Zeng, L.; Shannon, M.C.; Grieve, C.M. Evaluation of salt tolerance in rice genotypes by multiple agronomic parameters. Euphytica 2002, 127, 235-245. [CrossRef]

12. Meloni, D.A.; Oliva, M.A.; Martinez, C.A.; Cambraia, J. Photosynthesis and activity of superoxide dismutase, peroxidase and glutathione reductase in cotton under salt stress. Environ. Exp. Bot 2003, 49, 69-76. [CrossRef]

13. Hu, T.; Zhang, X.Z.; Sun, J.M.; Li, H.Y.; Fu, J.M. Leaf functional trait variation associated with salt tolerance in perennial ryegrass. Plant Biol. 2014, 16, 107-116. [CrossRef]

14. Li, X.; Han, S.; Wang, G.; Liu, X.; Amombo, E.; Xie, Y.; Fu, J. The Fungus Aspergillus aculeatus Enhances Salt-Stress Tolerance, Metabolite Accumulation, and Improves Forage Quality in Perennial Ryegrass. Front. Microbiol. 2017, 8, 1664. [CrossRef] [PubMed]

15. Li, R.; Shi, F.; Fukuda, K. Interactive effects of various salt and alkali stresses on growth, organic solutes, and cation accumulation in a halophyte Spartina alterniflora (Poaceae). Environ. Exp. Bot. 2010, 68, 66-74. [CrossRef]

16. Xie, Y.; Han, S.; Li, X.; Amombo, E.; Fu, J. Ameliorates of salt stress on bermudagrass by the fungus Aspergillus aculeatus. Mol. Plant-Microbe Interact. MPMI 2017, 30, 245-254. [CrossRef] [PubMed]

17. Zhu, J.K. Plant salt tolerance. Trends Plant Sci. 2001, 6, 66-71. [CrossRef]

18. Munns, R. Comparative physiology of salt and water stress. Plant Cell Environ. 2010, 25, 239-250. [CrossRef] [PubMed]

19. Zheng, K.; Hong-Ru, G.U.; Shen, Y.X.; Ding, C.L. Evaluation system of forage quality and research advances in forage quality breeding. Pratacultural Sci. 2006, 23, 57-61.

20. Hu, H.L.; Gao, M.; Lu, D.X. Grading Index (GI): A New Integrated Technique for Evaluation of Forage Quality. Anim. Husb. Feed. Sci. 2011, 32, 150-151. 
21. Jikun, Z.; Kaiwen, C.; Jinfang, X.; Xunlu, D.; Ming, H. A Comparison of Grading Index and Relative Feed Value in Forage Quality Evaluation. Feed Livest. 2008, 1, 30-32.

22. Soudek, P.; Katruáková, A.; Sedláek, L.; Petrová, Š.; Koó, V.; Marík, P.; Griga, M.; Vaněk, T. Effect of Heavy Metals on Inhibition of Root Elongation in 23 Cultivars of Flax ( Linum usitatissimum L.). Arch. Environ. Contam. Toxicol. 2010, 59, 194-203. [CrossRef] [PubMed]

23. Wang, Y.; Le, L.; Cui, W.; Sheng, X.; Shen, W.; Ren, W. Hydrogen sulfide enhances alfalfa (Medicago sativa) tolerance against salinity during seed germination by nitric oxide pathway. Plant Soil 2012, 351, 107-119. [CrossRef]

24. Sun, J.; Luo, H.; Fu, J.; Huang, B. Classification of Genetic Variation for Drought Tolerance in Tall Fescue using Physiological Traits and Molecular Markers. Crop Sci. 2013, 53, 647-654. [CrossRef]

25. Hu, L.; Li, H.; Pang, H.; Fu, J. Responses of antioxidant gene, protein and enzymes to salinity stress in two genotypes of perennial ryegrass (Lolium perenne) differing in salt tolerance. J. Plant Physiol. 2012, 169, 146-156. [CrossRef] [PubMed]

26. AOAC. Official Methods of Analysis, 16th ed.; (930.15); Association of Official Analytical Chemists: Washington, DC, USA, 1999.

27. AOAC. Ash of Animal Feed: (942.05) Official Methods of Analysis, 15th ed.; Association of Official Analytical Chemists: Washington, DC, USA, 1990.

28. Zhang, L.Y. Feed Analysis and Quality Test Technique; China Agricultural University Press: Beijing, China, 2007.

29. Palmonari, A.; Fustini, M.; Canestrari, G.; Grilli, E.; Formigoni, A. Influence of maturity on alfalfa hay nutritional fractions and indigestible fiber content. J. Dairy Sci. 2014, 97, 7729-7734. [CrossRef]

30. Fang, Z.; Hu, Z.; Zhao, H.; Yang, L.; Ding, C.; Lou, L.; Cai, Q. Screening for cadmium tolerance of 21 cultivars from Italian ryegrass (Lolium multiflorum Lam) during germination. Grassl. Sci. 2017, 63, 36-45. [CrossRef]

31. Xie, Y.; Luo, H.; Hu, L.; Sun, X.; Lou, Y.; Fu, J. Classification of genetic variation for cadmium tolerance in bermudagrass [cynodon dactylon (L.) pers.] using physiological traits and molecular markers. Ecotoxicology 2014, 23, 1030-1043. [CrossRef]

32. Grabherr, M.G.; Haas, B.J.; Yassour, M.; Levin, J.Z.; Thompson, D.A.; Amit, I.; Adiconis, X.; Fan, L.; Raychowdhury, R.; Zeng, Q.; et al. Full-length transcriptome assembly from RNA-Seq data without a reference genome. Nat. Biotechnol. 2011, $29,644-652$. [CrossRef]

33. Maas, E.V.; Hoffman, G.J.; Chaba, G.D.; Poss, J.A.; Shannon, M.C. Salt sensitivity of corn at various growth stages. Irrig. Sci. 1983, 4, 45-57. [CrossRef]

34. Lutts, S.; Kinet, J.M.; Bouharmont, J. Changes in plant response to $\mathrm{NaCl}$ during development of rice (Oryza sativa L.) varieties differing in salinity resistance. J. Exp. Bot. 1995, 46, 1843-1852. [CrossRef]

35. Maas, E.V.; Poss, J.A. Salt sensitivity of cowpea at various growth stages. Irrig. Sci. 1989, 10, 313-320. [CrossRef]

36. Hakim, M.A.; Juraimi, A.S.; Begum, M.; Hanafi, M.M.; Ismail, M.R.; Selamat, A. Effect of salt stress on germination and early seedling growth of rice (Oryza sativa L.). Afr. J. Biotechnol. 2010, 9, 1911-1918.

37. Robinson, P.H.; Grattan, S.G.; Grieve, C.M.; Poss, J.A.; Suarez, D.L. Biomass accumulation and potential nutritive value of some forages irrigated with saline-sodic drainage water. Anim. Feed. Sci. Technol. 2004, 111, 175-189. [CrossRef]

38. Kumar, D.B. Exogenous Application of Bio-regulators Improves Grain Yield and Nutritional Quality of Forage Cowpea (Vigna unguiculata). Int. J. Agric. Biol. 2014, 16, 759-765.

39. Assefa, G.; Ledin, I. Effect of variety, soil type and fertiliser on the establishment, growth, forage yield, quality and voluntary intake by cattle of oats and vetches cultivated in pure stands and mixtures. Anim. Feed. Sci. Technol. 2001, 92, 95-111. [CrossRef] 